\title{
A Chlorophyll Sensor for Automatic, Remote, Operation in the Marine Environment
}

\author{
J. Aiken \\ Natural Environment Research Council, Institute for Marine Environmental Research, Prospect Place, The Hoe PL1 3DH, \\ Devon, England
}

ABSTRACT: A chlorophyll sensor has been designed for remote applications in underwater-towed bodies and moored or buoyed sensor systems for measurement periods up to $60 \mathrm{~d}$. The sensor has alternative ranges of 0 to $100 \mathrm{mg} \mathrm{m}^{-3}{\mathrm{or} 0 \mathrm{to} 1000 \mathrm{mg} \mathrm{m}}^{-3}$ chlorophyll $a$, with a resolution of $0.1 \mathrm{mg} \mathrm{m}^{-3}$, and excellent long-term stability of calibration. Some results obtained with the sensor in the Undulating Oceanographic Recorder in the English Channel are presented.

\section{INTRODUCTION}

The Undulating Oceanographic Recorder (UOR) (Bruce and Aiken, 1975) was designed to overcome the limitations of single-depth sampling of the Continuous Plankton Recorder (CPR) (Hardy, 1939; Glover, 1962, 1967 ) and, at the same time, provide physical measurements of the marine environment. The standard instruments of the UOR are sensors for salinity, temperature and depth, interfaced to a magnetic tape data logger. The plankton sampling mechanism is that used in the CPR, sampling continuously on to silk with a mesh of $270 \mu \mathrm{m}$; this provides an adequate sub-sample of zooplankton species but phytoplankton is sampled poorly. This paper describes the development and performance of a sensor for chlorophyll $a$, which was designed to overcome the sampling deficiency of the CPR mechanism by providing a measure of potential primary production.

\section{DESIGN OF THE CHLOROPHYLL SENSOR}

Monitoring instruments carried by the UOR must be small, robust and capable of operating automatically under a wide range of environmental conditions. The electrical power consumption should be low and the output signal compatible with a simple recording device. For these reasons the design of the chlorophyll sensor was based on a simple fluorometer.

The fluorescence of chlorophyll is characterised by a broad excitation spectrum centred around $435 \mathrm{~nm}$ (blue) and a narrow emission spectrum at $675 \mathrm{~nm}$ (red) (Yentsch and Menzel, 1963). Chlorophyll $a, b$ and $c$ and the degradation products through zooplankton grazing, phaeophytin $a, b$ and $c$ all have similar fluorescence spectra although chlorophyll $a$ is the dominant pigment in marine phytoplankton; judicious choice of wavelength selection filters for the fluorescence radiation can minimise the contribution from the other pigment fluorescences detected (see Loftus and Carpenter, 1971).

A schematic diagram of the optical system of the chlorophyll sensor is shown in Figure 1. The optical arrangement is symmetrical about the sample cell, incorporating one-to-one optics. No expertise in optics is required for the construction of the sensor which can be assembled by any small electronics and mechanical workshop or engineering company. The specification and sources of the major components of the sensor are listed in Table. 1.

To minimise the electrical power requirements and to optimise the excitation of fluorescence, a flashing xenon lamp was chosen as the radiation source. The xenon discharge has a broad spectral emission, extending from about $200 \mathrm{~nm}$ in the ultra violet well into the infra-red beyond $1100 \mathrm{~nm}$, with a high blue content from 350 to $500 \mathrm{~nm}$. With an input energy of approximately $2 \mathrm{~J} \mathrm{flash}^{-1}$, the theoretical duration of the flash is about 10 to 15 microseconds and the theoretical light output is of the order of $5.10^{16}$ photons flash-1 $\mathrm{nm}^{-1}$ in the range $400 \mathrm{~nm}$ to $500 \mathrm{~nm}$. The flash is generated by the charge from a $47 \mu \mathrm{F}$ capacitor, charged to $300 \mathrm{~V}$ by a $5 \mathrm{~V}$ to $300 \mathrm{~V}$ dc to dc converter, 


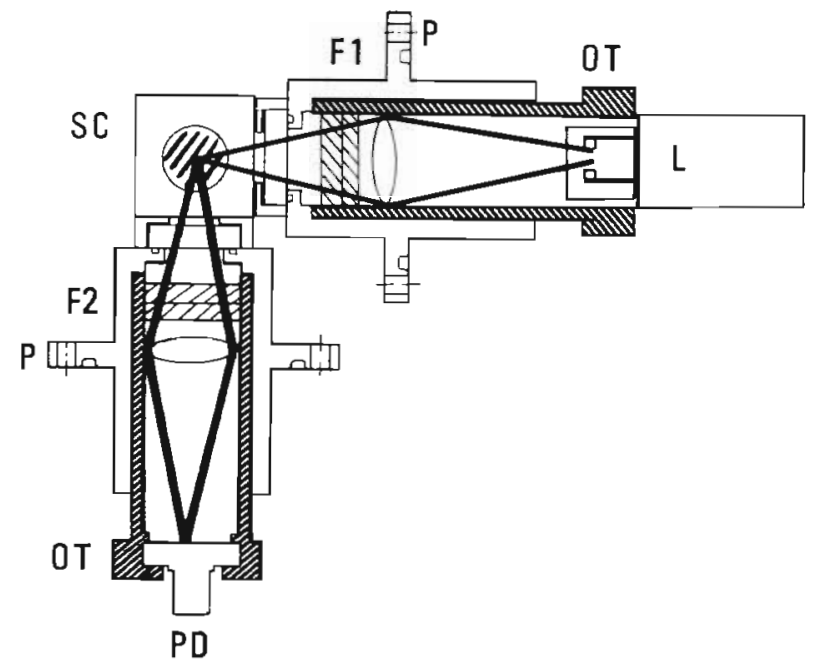

Fig. 1. Chlorophyll sensor. Schematic cross-sectional diagram of optical system. L: flash lamp and litepac F $_{i}$ OT: optics assembly tubes; P: pressure ports; Fl: blue filters; SC: sample cell; F2: red filters; PD: photodetector

triggered at a preselected rate once every $10 \mathrm{~s}$ by a master clock, so that the average power consumption is restricted to less than $0.2 \mathrm{~W}$. To isolate the band of blue excitation radiation from the wide band of radiation emitted by the source, two blue optical filters are used, which together eliminate all radiation beyond $580 \mathrm{~nm}$ (Fig. 2)

Two red filters are used to isolate the fluorescence radiation from the background: a red blocking filter which transmits no radiation below $620 \mathrm{~nm}$ and a nar-
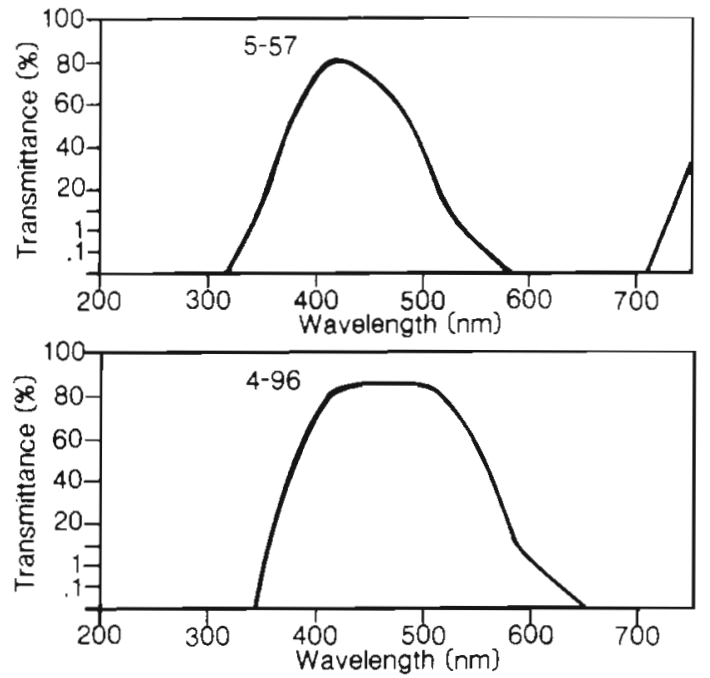

Fig. 2. Optical transmission spectra of the blue filters for the source radiation in the flash gun (Corning CS 5-57 top and CS $4-96$ bottom)

row band interference filter (Fig. 3). The interference filter has a red blocking filter cemented to one side which gives it a sharp cut-on at $650 \mathrm{~nm}$, thus attenuating significantly the fluorescence from chlorophyll bor $c$ pigments present in the sample (Loftus and Carpenter, 1971).

A solid state silicon photodiode is used as photodetector. The photodetector signal is amplified by two low-noise operational amplifiers, the first in noninverting mode (high-input impedance) to minimise

Table 1. Specifications and sources of components of chlorophyll sensor

Biconvex lenses

Windows

Flash lamp

Flash capicator

Flash power supply

Primary power

Blue filters

Red filters

Photo detector

Photo-amplifier

Power supplies

Recording medium
$25 \mathrm{~mm}$ od, $25 \mathrm{~mm}$ focal length, crown glass, Oriel Corporation

$25 \mathrm{~mm}$ od, $6 \mathrm{~mm}$ thick, crown glass, Oriel Corporation

FX108 AU with Litepac FY-505, E. G. \& G. Incorporated

$47 \mu \mathrm{F}, 300 \mathrm{~V}$ Tantalum, Hughes

$5 \mathrm{~V}$ to $300 \mathrm{~V} \mathrm{dc} / \mathrm{dc} \mathrm{K}$. E. Developments Ltd., Type 701

5 Manganese Alkaline D cells, Mallory Type MN 1300

Capacity $10 \mathrm{Ah}$, lifetime $50 \mathrm{~h}$ at 10 slash period

$25 \mathrm{~mm}$ od, type 5-57 and type 4-96, Corning Glass Works

$25 \mathrm{~mm}$ od, type 2-58, Corning Glass Works Interference filter $680 \mathrm{~mm}, 1 / 2$ width $50 \mathrm{~mm}$, Oriel Corporation

Silicon photodiode, United Detector Technology Type PIN 8LC

Two JFET operational amplifiers, National Semiconductors Type LF 356H Two sample and hold amplifiers, National Semiconductors Type LF 398H

$+5 \mathrm{~V}$ and $-5 \mathrm{~V}$ each 4 Manganese Alkaline AA Cells Mallory Type MN 1500 Capacity $1.6 \mathrm{Ah}$, lifetime $20 \mathrm{~h}$ at $20^{\circ} \mathrm{C}$, including tape recorder power.

Standard C120 magnetic tape cassette using either Minature Analogue Tape Recorder, range $0-100 \mathrm{mV}, \pm 1 \%$ resolution or Miniature Digital

Tape Recorder, range $0-1 \mathrm{~V}, \pm 0.1 \%$ resolution both Oxford Medical Systems Ltd

Flash Lamp and Detector Unit Electronic Modules, or the fully assembled Chlorophyll sensor can be supplied by Almondbury Development Company, Yeovil, England 
photodiode noise, producing a non-linear response. The amplified pulse of fluorescence radiation is peak detected and converted to a dc signal by two sampleand-hold amplifiers in tandem, so that voltage droop is less than $0.1 \mathrm{mV} \mathrm{s}^{-1}$. The sample-and-hold amplifiers are triggered and reset by the signal from an auxiliary photodiode, monitoring the flash from the source directly, thus isolating the flash gun and detector circuitry to eliminate noise and spurious pick-up.

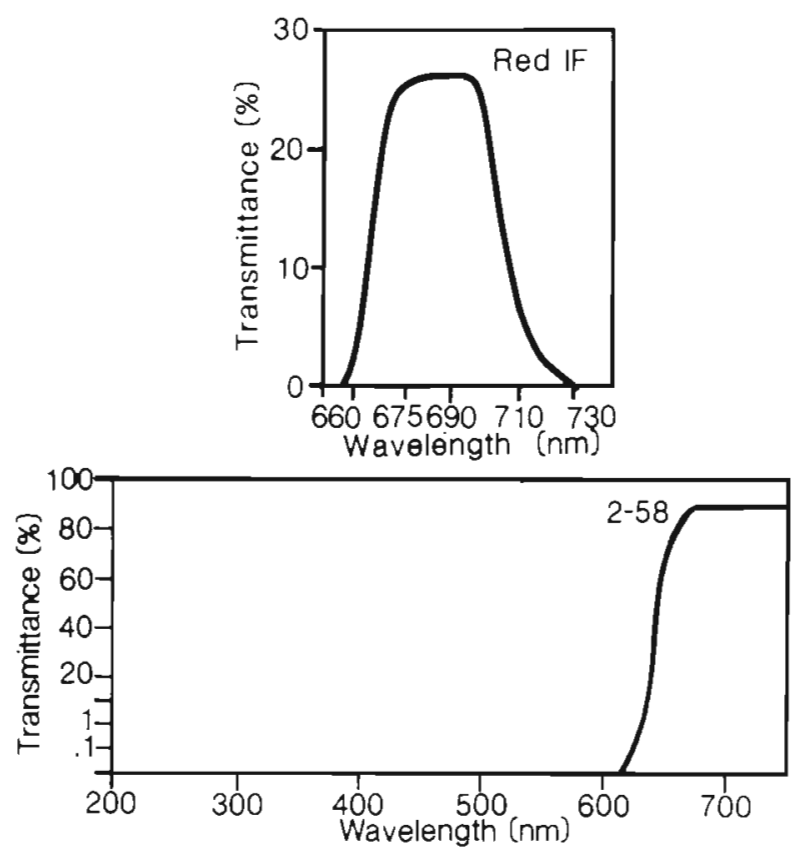

Fig. 3. Optical transmission spectra of the red interference filter (top) and the red blocking filter (Corning CS 2-58) for the fluorescence radiation

In the laboratory, the dc output signal from the detector electronics is measured by a digital voltmeter. For field operations, the output signal is recorded onto a magnetic tape cassette by a Miniature Analogue Tape Recorder (MATR) (Aiken, 1980) or a Miniature Digital Tape Recorder (MDTR): the MATR can accommodate signals in the range 0 to $100 \mathrm{mV}$ and records the signal to tape using a pulse width modulation technique with a resolution about $\pm 1 \%$ full scale; the MDTR digitises the signal and records the digital value on tape. The MDTR is preferred because of its increased range ( 0 to $1 \mathrm{~V}$ ) and improved resolution (1 part in 1024 , about $0.1 \%$ ). Both the flash gun circuit, and the photodetector amplifier and electronic circuitry incorporate an 'in-water' switch, for automatic operation when the instruments are launched. The switch maintains battery power to all circuits for about 5 min after the instruments are recovered to provide 'on deck' readings for verification of the data obtained.

\section{ASSESSMENT OF CHLOROPHYLL SENSOR PERFORMANCE}

Sensitivity, resolution and full scale range of the instrument are dependent on several factors: flash intensity, primary and secondary filter transmission, photodetector sensitivity and amplifier gain. Basic sensitivity and full scale range are regulated by adjusting the gain of the photodetector circuitry; the resolution is equated to a signal-to-noise ratio of unity.

With a fixed flash intensity and photodetector amplifier gain, the full scale range and resolution of the sensor are determined by direct calibration against samples of unialgal laboratory cultures or natural phytoplankton populations of known chlorophyll a concentration (determined by extracting the chlorophyll a from sub-samples of the calibration culture and measuring the concentration in a spectrophotometer, as described by Strickland and Parsons, 1972). The samples are injected with DCMU (to a final concentration of $10 \mu \mathrm{M}$ ) to inhibit photosynthesis and allow all the chlorophyll molecules present in the sample to fluoresce (Slovacek and Hannan, 1977). Recent work in this laboratory has shown the necessity for caution when using DCMU with unialgal laboratory cultures in varying states of light adaptation. With DCMU present, the intensity of the radiation exciting fluorescence must be sufficient to excite all molecules. At lower than optimum light levels, inconsistent results occur.

A typical calibration curve of in vivo fluorescence (in $\mathrm{mV}$ ) for two unialgal laboratory cultures injected with DCMU versus extracted chlorophyll a concentration, is presented in Figure 4 (logarithmic scales) ranging over two orders of magnitude; the data conform to a straight line of slope $78 \mathrm{mV}$ ( $\mathrm{mg}$ Chla $\left.\mathrm{m}^{-3}\right)^{-1}$ with a regression

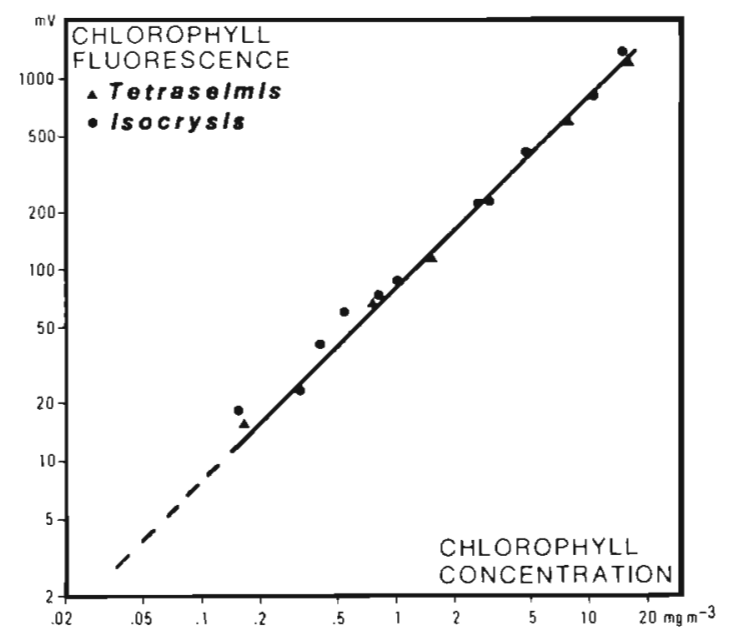

Fig. 4. Calibration curve of in vivo chlorophyll fluorescence (in $\mathrm{mV}$ ) for two unialgal laboratory cultures injected with DCMU, versus extracted chlorophyll a concentration 

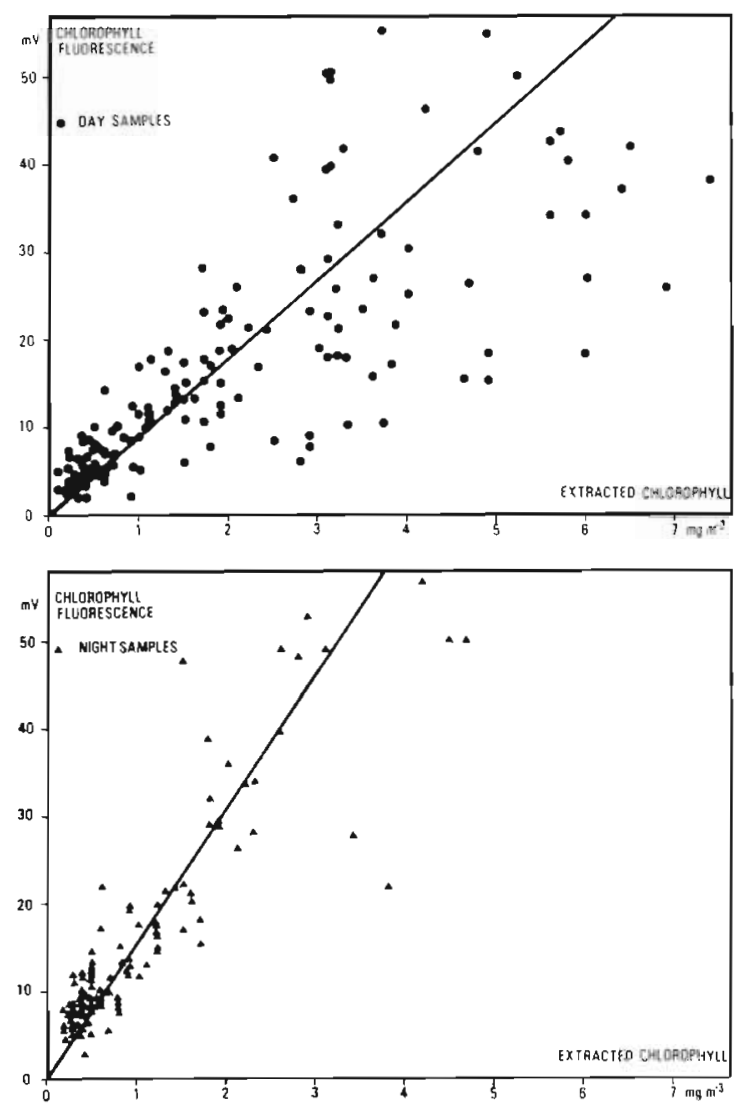

Fig. 5. Field measurements of chlorophyll sensor in vivo fluorescence versus extracted chlorophyll a from simultaneous discrete samples. Top: 165 day stations (slope $=9.14, r=$ 0.81). Bottom: 109 night stations (slope $=15.51, I=0.89$ )

coefficient, $r=0.9986$. The amplifier gain in this case was 1000 giving typically $4 \mathrm{mV}$ of amplifier noise, setting sensor resolution at $0.05 \mathrm{mg} \mathrm{m}^{-3}$. The sensor calibration is linear up to a fluorescence signal about $1000 \mathrm{mV}$, but the photodetector/amplifier combination, and/or self absorption of the fluorescence radiation in the sample, produces a non-linearity of response for high chlorophyll concentrations

Stability of calibration, estimated from the repeatability of the signal from a standard fluorescence sample, was found to be within 1 to $2 \%$ over a period of several months, independent of flash gun battery voltage (range $5 \mathrm{~V}$ to $7.5 \mathrm{~V}$ ) and detector battery voltages (range \pm 5 to $\pm 6 \mathrm{~V}$ ) and independent of temperature over the operational range of $0^{\circ}$ to $30^{\circ} \mathrm{C}$.

The performance of the sensor in the field was assessed by shipboard determinations during a series of cruises in the Bristol Channel and Celtic Sea in 1977 and in the English Channel in 1978, covering a wide range of phytoplankton assemblages and physiological conditions. Surface sea water (from about $2 \mathrm{~m}$ depth) was pumped on board the vessel and in vivo fluorescence measured continuously using a Turner fluorometer and the chlorophyll sensor. Surface sea water samples were taken every $30 \mathrm{~min}$ for filtration and extraction of chlorophyll and, at selected stations, from several depths (typically $5 \mathrm{~m}, 10 \mathrm{~m}, 15 \mathrm{~m}$, and $25 \mathrm{~m}$ ). Analysis of the data shows that the measurement of in vivo chlorophyll fluorescence by the two fluorometers is comparable. The relationship between the sensor measurements and the concentration of extracted chlorophyll is presented in Figure 5, showing clearly a difference between the day and night stations; the fluorescence yield per unit chlorophyll is much lower and the scatter of the points much greater by day. These data are consistent with the suggestion of Slovacek and Hannan (1977) that only those chlorophyll molecules not active in photosynthesis are available for fluorescence; the proportion of inactive chlorophyll (fluorescing) is variable by day and generally constant by night.

\section{SURVEY DEPLOYMENTS OF THE CHLOROPHYLL SENSOR}

The chlorophyll sensor has been designed for automatic, remote operation in data buoys and underwater towed vehicles. Its performance has been assessed during trials in the Fast Continuous Plankton Recorder (FCPR) and the UOR deployed from 'ships of opportunity'. The instruments are prepared in the laboratory and dispatched to the towing vessel for deployment by the vessel's crew; generally no scientist accompanies the instruments or participates in the launch and recovery operations.

During 1979 the UOR Mark 2 containing the chlorophyll sensor and sensors for salinity, temperature and depth was towed from the Plymouth to Roscoff ferry, MV 'Cornouailles', at monthly intervals across the western English Channel. Figure 6 shows measurements of chlorophyll recorded by the UOR Mark 2 for return day and night tows by the Plymouth-Roscoff ferry. Although the data points have not been corrected for tidal movement of the water mass, the two data sets show a general similarity in the patterns of distribution of chlorophyll. The values at night were generally higher indicating the increased fluorescence at night when photosynthesis is minimal. Simultaneous temperature measurements show that a thermocline exists at the northern end of the route corresponding approximately to the $13^{\circ} \mathrm{C}$ isotherm shown in Figure 6 and forming the lower boundary to the highest concentrations of chlorophyll; the southern end was unstratified (about $14.5^{\circ} \mathrm{C}$ from top to bottom).

The data being gathered by the UOR Mark 2 in a ship-of-opportunity survey of the western English 


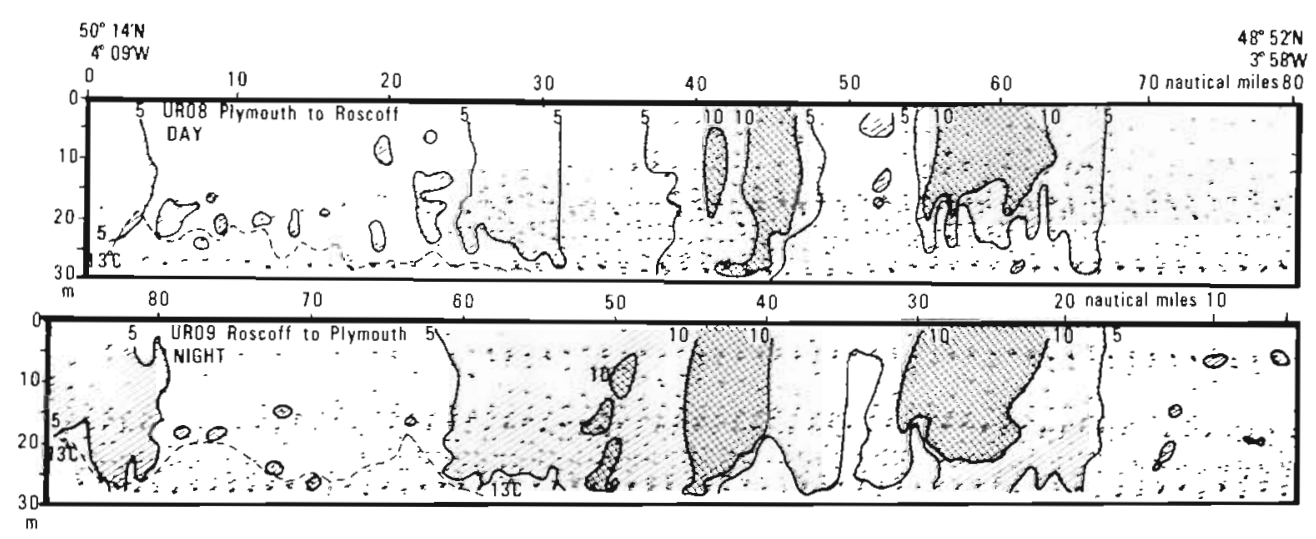

Fig. 6. Computer processed plots of chlorophyll concentration (in $\mathrm{mg} \mathrm{m}^{-3}$ ) with depth $(\mathrm{m}$ ) for return day/night tows of the UOR Mark 2 across the English Channel in August 1979; UR08, $14.40 \mathrm{~h}$ to $19.29 \mathrm{~h}, 23$ August 1979, Plymouth to Roscoff and UR09, $23.34 \mathrm{~h}, 23$ August 1979 to $04.20 \mathrm{~h}, 24$. August 1979, Roscoff to Plymouth; the $13^{\circ} \mathrm{C}$ isotherm, corresponding approximately to the thermocline, is shown as a dashed line; each dot represent a separate measurement

Channel are being used to study the seasonal and spatial variability of chlorophyll and its relationship with primary production in this area

Acknowledgements. I acknowledge the assistance of the officers and crew of the MV 'Cornouailles' (Brittany Ferries Limited) and the research vessels RV 'Edward Forbes' (Natural Environment Research Council), RV 'Sarsia' and RV 'Squilla' (Marine Biological Association) which have been used in this programme. This work forms part of the programme of the Institute for Marine Environmental Research which is a component body of the Natural Environment Research Council.

\section{LITERATURE CITED}

Aiken, J. (1980). A marine environmental recorder. Mar. Biol. 57: $237-240$

Bruce, R. H., Aiken, J. (1975). The Undulating Oceanographic Recorder - a new instrument system for sampling plank- ton and recording physical variables in the euphotic zone from a ship underway. Mar. Biol. 32: 85-97

Glover, R. S. (1962). The Continuous Plankton Recorder Rapp. P.-v. Réun. Cons. perm. int. Explor. Mer 153: 8-15

Glover, R. S. (1967). The Continuous Plankton Recorder Survey of the North Altantic. Symp. zool. Soc. Lond. 19: 189-210

Hardy, A. C. (1939). Ecological investigations with the Continuous Plankton Recorder. Object, plan and methods. Hull Bull mar. Ecol. 1: 1-57

Loftus, M. E., Carpenter, J. E. (1971). A Fluorometric Method for Determining Chlorophylls $a, b$ and c. J. mar. Res. 29: 319-338

Slovacek, R. E., Hannan, P. J. (1977). In vivo fluorescence determinations of phytoplankton chlorophyll a. Limnol. Oceanogr. 22: 919-925

Strickland, J. D. H., Parsons, T R. (1972). A practical handbook of seawater analysis, 2nd ed. Bull. Fish. Res. Bd Can. 167: $1-311$

Yentsch, C. S., Menzel, D. W. (1963). A method for the determination of phytoplankton chlorophyll and phaeophytin by fluorescence. Deep Sea Res. 10: 221-231

This paper was presented by Dr. R. S. Glover, it was accepted for printing on October 7, 1980 